\title{
Delivery Mechanism Code
}

National Cancer Institute

\section{Source}

National Cancer Institute. Delivery Mechanism Code. NCI Thesaurus. Code C93549.

A coded value specifying how something is to be conveyed. 